\title{
In search of an ideal single-session penicillin schedule for the treatment of gonorrhoea in Uganda
}

\author{
O. P. ARYA \\ Department of Preventive Medicine, Makerere University Medical School \\ AND \\ C. B. BOSA \\ Makerere University Health Service, Kampala, Uganda
}

Gonorrhoea, both uncomplicated and complicated, is very common in Uganda (Arya, 1973). During the last 12 months one of us (O.P.A.) had the opportunity of ascertaining the diagnostic and treatment practices for gonorrhoea in many urban and rural medical units in Uganda. Some private practitioners were also interviewed. The findings in this enquiry were revealing, though not surprising, and have been discussed elsewhere (Arya and Bennett, 1973). It is, however, relevant to mention here that the most widely practised 'regime' for the treatment of gonorrhoea in the upcountry medical units was longacting procaine penicillin in oil with aluminium monostearate (PAM) given in one intramuscular injection of $2 \mathrm{ml}$. (600,000 units) or a similar dose daily for a 'few' days. Several of the private practitioners preferred tetracycline capsules, usually in multiple doses, with or without an 'injection'. Most of the schedules mentioned were obviously inadequate or inappropriate for the treatment of gonorrhoea because of the prevailing gonococcal sensitivity pattern in Uganda (Arya and Phillips, 1970). Above all, the concept of full and effective treatment with a single dose of an appropriate preparation was not widely known or appreciated.

It is universally agreed that an ideal drug for the treatment of gonorrhoea should be cheap, nontoxic, highly effective in a single dose and should not produce any undesirable microbiogenic or allergic effects. It seems unlikely that another drug as cheap, safe, and effective as penicillin was when first introduced will ever by discovered. However, in spite of the high incidence of less sensitive strains of gonococci in many parts of the world (Willcox, 1972), penicillin still comes nearest to the fulfilment of the above criteria when given in high enough doses and appropriate forms.

Received for publication December 8, 1972

Address for reprints: Dr. O. P. Arya, Special Clinic, Liverpool Royal Infirmary, Pembroke Place, Liverpool L3 5PU
The purpose of this paper is to compare five different single-session penicillin schedules in an attempt to find the most effective and economical therapy relevant to the situation in Uganda. One of these, procaine penicillin 2.4 m.u., has until recently been the standard treatment of acute gonorrhoea for men treated at the Makerere University Health Centre, but it has recently been giving rather unfavourable results (Arya, Rao, and Nnochiri, 1971).

\section{Material and methods}

\section{PATIENTS}

460 male university students (24 married) with urethral discharge were studied between July, 1970 and September, 1972.

In 192 cases, this was the very first attack. The other 268 patients had already had one to ten attacks of urethritis since joining the university. 646 attacks of gonococcal urethritis seen and treated by either of us formed the basis of this study.

41 patients who had been treated unsuccessfully elsewhere before coming to our clinic, and fifteen with a history of penicillin allergy, were excluded from this study and treated with other drugs. Of the remaining 590 cases, 485 were seen within 1 to 2 days of the appearance of urethral discharge and only seventeen after one week. Two had no symptoms and were not aware of any discharge. The source of infection was barmaids or casual acquaintances in 340 cases, a friend or continuing acquaintance in 223, and a wife in six; the source was uncertain in the remaining 21 cases because of multiple contacts (including the wife in two cases).

\section{LABORATORY INVESTIGATIONS}

Gram-stained urethral smears were made in all cases. Gonorrhoea was diagnosed if typical Gram-negative intracellular diplococci were seen. Persistence of urethral discharge after 2 weeks was considered to indicate nongonococcal urethritis (NGU) if a smear did not reveal any Gram-negative intracellular diplococci.

Blood samples were taken for routine serological tests for syphilis on the first day and again after 3 months. 
TREATMENT

After excluding those with a history of penicillin allergy, the patients were randomly allocated to one of the following schedules:

(i) Aqueous procaine penicillin $2.4 \mathrm{~m} . \mathrm{u}$. (Flopen 'Hoechst') intramuscularly in a single dose into a buttock.

(ii) Procaine penicillin $2.4 \mathrm{~m} . \mathrm{u}$. as above followed immediately by $1 \mathrm{~g}$. ampicillin orally in $500 \mathrm{mg}$. capsules (Penbritin, Beecham Research Laboratories). The rationale of this combination has been described by Fluker and Hewitt (1969).

(iii) Procaine penicillin $\star 3 \mathrm{~m} . \mathrm{u}$. intramuscularly in one dose into a buttock.

(iv) Procaine penicillin $3 \mathrm{~m} . \mathrm{u}$. as in (iii) above and at the same time probenecid $1 \mathrm{~g}$. orally in two tablets of $500 \mathrm{mg}$. each (Benemid-Merck Sharp and Dohme). The combination of these two drugs has given excellent results in S.E. Asia where there is a very high incidence of gonococcal strains less sensitive to penicillin (Holmes, Johnson and Floyd, 1967).

(v) Probenecid $1 \mathrm{~g}$. orally followed $30 \mathrm{~min}$. later by benzyl penicillin 5 m.u. (Crystapen, Glaxo laboratories) made up with $8 \mathrm{ml}$. 0.5 per cent. lignocaine solution and given into one buttock. Olsen and Lomholt (1969) achieved a 99 per cent. cure rate with this combination in Greenland.

Ampicillin capsules and probenecid tablets were swallowed in the presence of the physician or nurse.

Schedules (iii) and (iv) were introduced into the trial in July, 1971.

\section{FOLLOW-UP}

All patients were asked to return after 3 days, 1 week, 2 weeks, 3 weeks, and 3 months, and the same routine was followed as has been described earlier (Arya and others, 1971).

\section{RELAPSE AND RE-INFECTION}

Our criteria to distinguish relapse from re-infection have also been described earlier (Arya and Phillips, 1970). Most of our treatment failures were seen within one week and the remainder in the second week. When in doubt, we re-interviewed our patients a few days after treatment. Any patient with a recurrence within 2 weeks who admitted re-exposure to risk of infection was considered to have been re-infected; these patients were not classed as failures or cures and were omitted from the total when the cure rate was calculated. In our experience a period of 2 to 3 weeks is adequate to determine the outcome of treatment of gonorrhoea in men. Moreover, we consider this period to be realistic and almost a threshold limit beyond which many of our youths apparently cannot maintain abstinence. One student had ten attacks of urethritis within 6 months and another had four attacks in 4 months. However, almost 30 per cent. completed 3 months' follow-up. All were followed up for a minimum period at of least 2 weeks except nine who were lost to the

^Flopen 'Hoechst', which we have used for several years, is a ready-touse aqueous suspension in vials of $3 \mathrm{~m}$.u.; one full vial is easy to administer and does away with any measuring - unlike in schedule (i) above. study because they left the university soon after treatment. Fourteen who admitted re-exposure within 2 weeks were considered to have been re-infected and were excluded when the cure rate was calculated. There were many more later recurrences after 2 weeks due to reinfection.

\section{Results}

The Table (overleaf) shows the results of treatment of the 590 new episodes with the five different schedules.

(i) Procaine penicillin 2.4 m.u. (125 cases) gave a cure rate of 90.3 per cent.

(ii) Procaine penicillin 2.4 m.u. plus ampicillin $1 \mathrm{~g}$. (143 cases) gave a cure rate of $97 \cdot 1$ per cent. One patient developed a hypersensitivity reaction.

(iii) Procaine penicillin 3 m.u. (90 cases) gavi a cure rate of 89.8 per cent.

(iv) Procaine penicillin 3 m.u. plus probenecid $1 \mathrm{~g}$. (103 cases) gave a cure rate of $97 \cdot 1$ per cent.

(v) Probenecid $1 \mathrm{~g}$. orally followed by benzyl penicillin 5 m.u. (129 cases) gave a cure rate of 96.8 per cent. Four patients developed hypersensitivity reactions.

All but one of the 31 failures on the above schedules were successfully treated with an alternative schedule. The one exception, after having failed on Schedules (iii) and (iv) and an injection of kanamycin $2 \mathrm{~g}$. was finally cured by Schedule (v).

All of the 41 cases treated unsuccessfully elsewhere (not included in the Table) had presumably received penicillin in varying amounts and some had also received 'a few capsules'. Nine such patients received procaine penicillin $2.4 \mathrm{~m}$.u. and seven were cured; fourteen were treated with the combination of procaine penicillin and ampicillin, ten were cured and one not followed; six were treated with the combination of procaine penicillin and probenecid and all were cured; the remaining twelve were treated with the probenecid and benzyl penicillin combination, eleven were cured and one re-infected.

\section{Discussion}

The results obtained with procaine penicillin alone in doses of 2.4 or $3 \mathrm{~m}$.u. are rather unfavourable. In Uganda the public medical services are so overwhelmed by the patient load that it is hardly possible to undertake a proper follow-up in the great majority of cases. For this reason any treatment given must be as effective and as simple as possible.

Of the three highly effective schedules presented in this study, the probenecid and benzyl penicillin combination (Schedule $v$ ) requires the preparation of penicillin with lignocaine solution and an extra 
TABLE Results of treatment with five different schedules

\begin{tabular}{|c|c|c|c|c|c|c|c|c|c|}
\hline \multirow{2}{*}{\multicolumn{2}{|c|}{ Schedule }} & \multicolumn{2}{|c|}{ No. of episodes } & \multicolumn{6}{|l|}{ Results } \\
\hline & & \multirow{2}{*}{$\begin{array}{l}\text { Treated } \\
125\end{array}$} & \multirow{2}{*}{$\begin{array}{l}\text { Followed } \\
120\end{array}$} & $1 s t w k$ & $2 n d w k$ & \multirow{2}{*}{$\begin{array}{l}N G U \\
18\end{array}$} & $1 s t w k$ & $2 n d w k$ & \multirow{2}{*}{$\begin{array}{l}\begin{array}{l}\text { Cure rate } \\
\text { per cent. }\end{array} \\
90 \cdot 3\end{array}$} \\
\hline & $\begin{array}{l}\text { Procaine penicillin } 2.4 \text { m.u. } \\
\text { intramuscularly }\end{array}$ & & & 10 & 1 & & 4 & 2 & \\
\hline (ii) & $\begin{array}{l}\text { Procaine penicillin } 2.4 \mathrm{~m} . \mathrm{u} \text {. } \\
\text { intramuscularly and ampicillin } 1 \mathrm{~g} \text {. } \\
\text { orally at the same time }\end{array}$ & 143 & 140 & 3 & 1 & 20 & 1 & 1 & $97 \cdot 1$ \\
\hline (iii) & $\begin{array}{l}\text { Procaine penicillin } 3 \mathrm{~m} . \mathrm{u} . \\
\text { intramuscularly }\end{array}$ & 90 & 90 & 8 & 1 & 9 & 1 & 1 & $89 \cdot 8$ \\
\hline (iv) & $\begin{array}{l}\text { Procaine penicillin } 3 \mathrm{~m} . \mathrm{u} \text {. plus } \\
\text { probenecid } 1 \mathrm{~g} \text {. orally at the same time }\end{array}$ & 103 & 103 & 1 & 2 & 5 & - & 1 & $97 \cdot 1$ \\
\hline (v) $\frac{1}{\mathrm{~F}}$ & $\begin{array}{l}\text { Probenecid } 1 \mathrm{~g} \text {. orally and benzyl } \\
\text { penicillin } 5 \mathrm{~m} \text {.u. intramuscularly } \\
30 \mathrm{~min} \text {. later }\end{array}$ & 129 & 128 & 3 & 1 & 17 & 2 & 1 & $96 \cdot 8$ \\
\hline
\end{tabular}

aPercentage of those followed excluding re-infections

30 min. wait (although Gray, Phillips, and Nicol 1970) allowed an interval of only $15 \mathrm{~min}$. and obtained a 99.5 per cent. cure rate). Simple though this procedure may seem, it could not be easily organized in the busy multi-purpose clinics throughout Uganda. Moreover, this combination is not cheap (Arya and Bosa, 1972).

The combination of an injection of procaine penicillin $2.4 \mathrm{~m}$.u. and ampicillin $1 \mathrm{~g}$. orally may appeal to private practitioners whose patients are apparently not satisfied with a mere injection. Although this treatment is expensive (Arya and Bosa, 1972), private practitioners can afford it and it can be administered at the clinic in one session under supervision.

The remaining schedule, i.e. the combination of procaine penicillin $3 \mathrm{~m} . \mathrm{u}$. and probenecid $1 \mathrm{~g}$., appears to us to be the nearest to an ideal singlesession penicillin schedule. It is not only effrctive (97.1 per cent. cure rate) and the cheapest of the three most effective schedules presented in this study, but can be easily administered. Furthermore, the more prolonged penicillinaemia achieved by $3 \mathrm{~m}$.u. procaine penicillin may be assumed to be more effective in aborting cases of incubating syphilis, which is common in Uganda, than that achieved by benzyl (crystalline) penicillin.

The present treatment practices in Uganda using P.A.M., often given in small repeated doses, especially in many upcountry medical units, are no doubt continuing to encourage the emergence and spread of less sensitive strains. If cost has been one of the main considerations for these practices, then it has been a case of false economy in terms of both time and money (Arya and Bosa, 1972). We consider that
P.A.M. no longer merits this use, either medically or economically, in the treatment of gonorrhoea in Uganda at the present time.

Although the gonococcal sensitivity pattern may vary nationally and internationally, it is interesting to note that an extensive investigation recently carried out in neighbouring Kenya (Verhagen, Van Der Ham, Heimans, Kranendonk and Maina, 1971) revealed almost similar trends to those reported by Arya and Phillips (1970) from Uganda. Verhagen and others also noted inadequate gonorrhoea treatment in several Kenya Hospitals. It is likely that a similar situation exists in many other parts of Africa. The single-dose treatment schedules shown to be effective in our investigation could well contribute towards halting this trend, but it may be an uphill task unless considerable improvements in diagnostic and treatment facilities are made available.

\section{Summary}

The treatment of gonorrhoea in men with five different single-session penicillin schedules is described; 590 infections in 460 university students were assessed.

Procaine penicillin in doses of 2.4 and 3 m.u. gave unfavourable cure rates of 90.3 and 89.8 per cent. respectively. Procaine penicillin 2.4 m.u. with ampicillin $1 \mathrm{~g}$. by mouth cured $97 \cdot 1$ per cent., benzyl penicillin $5 \mathrm{~m} . \mathrm{u}$. preceded by probenecid $1 \mathrm{~g}$. cured 96.8 per cent., and the combination of procaine penicillin $3 \mathrm{~m} . \mathrm{u}$. with probenecid $1 \mathrm{~g}$. gave a cure rate of 97.1 per cent. On the basis of cost and ease of administration, the last schedule (i.e. the combination of procaine penicillin and probenecid) is 
recommended for general use for the treatment of gonorrhoea in Uganda.

\section{References}

ARYA, O. P. (1973) Brit. F. vener. Dis., 49, 134

and BENNETT, F. J. (1973) 'The use and misuse of medicines in relation to some sexually transmitted diseases in Uganda'. Paper presented at the Annual Scientific Conference of the East African Medical Research Council at Nairobi, Kenya, in February, 1973

and Bosa, C. B. (1972) Uganda med. F., 1, 122 and Phillips, I. (1970) Brit. F. vener. Dis., 46, 149

-

Fluker, J. L., and HewitT, A. B. (1969) Ibid., 45, 317

Gray, R. C. F., Phillips, I., and Nicol, C. S. (1970) Ibid., 46, 401

Holmes, K. K., Johnson, D. W., and Floyd, T. M. (1967) F. Amer. med. Ass., 202, 461

Olsen, G. A., and Lomholt, G. (1969) Brit. F. vener. Dis., 45, 144

Verhagen, A. R., Van Der Ham, M., Heimans, A. L., KRANENDONK, O., and MaINA, A. N. (1971) Bull. Wld Hlth Org., 45, 707
WILlcox, R. R. (1972) Brit. f. vener. Dis., 48, 163

Recherche d'un schéma idéal de traitement de la gonococcie par injection unique de pénicilline en Ouganda

SOMMAIRE

On décrit cinq schémas de traitement de la gonococcie masculine par une seule injection de pénicilline; l'action de 590 injections chez 460 étudiants fut observée.

La pénicilline-procaine aux doses de 2,4 et de 3 m.u. a donné des taux de guérisons insuffisants de 90,3 et de 89,8 pour cent, respectivement. La pénicilline-procaine à $2,4 \mathrm{~m}$.u. associée à $1 \mathrm{~g}$ d'ampicilline administrée par voie buccale a donné 97,1 pour cent de guérisons, la benzylpénicilline à $5 \mathrm{~m}$.u. précédée par $1 \mathrm{~g}$ de probénécide, 96,8 pour cent et la combinaison de $3 \mathrm{~m}$.u. de pénicillineprocaīne avec $1 \mathrm{~g}$ de probénécide 97,1 pour cent. En considérant la dépense et la facilité d'administration, cette dernière modalité (c'est à dire la combinaison de pénicilline-procaine et de probénécide) est recommandée pour un emploi général dans le traitement de la gonococcie en Ouganda. 